\title{
Glucoamylase:: green fluorescent protein fusions to monitor protein secretion in Aspergillus niger
}

\author{
Caroline L. Gordon, ${ }^{1}$ Vahid Khalaj, ${ }^{1}$ Arthur F. J. Ram, ${ }^{2}$ David B. Archer, ${ }^{3}$ \\ Jayne L. Brookman, ${ }^{1}$ Anthony P. J. Trinci, ${ }^{1}$ David J. Jeenes, ${ }^{3}$ \\ John H. Doonan, ${ }^{5}$ Brian Wells, ${ }^{5}$ Peter J. Punt, ${ }^{4}$ \\ Cees A. M. J. J. van den Hondel ${ }^{4}$ and Geoffrey D. Robson ${ }^{1}$
}

Author for correspondence: Geoffrey D. Robson. Tel: +44 161275 5048. Fax: +44 1612755656. e-mail: Geoff.Robson@man.ac.uk

\footnotetext{
1 School of Biological Sciences, Stopford Building, University of Manchester, Manchester M13 9PT, UK

2 Centre for Phytotechnology, Institute for Molecular Plant Sciences, Clusius Laboratory, Wassenaarseweg 64, 2333 Al Leiden, The Netherlands

3 Department of Genetics and Microbiology, Institute of Food Research, Norwich Laboratory, Norwich Research Park, Colney, Norwich NR4 7UA, UK

4 TNO Nutrition and Food Research Institute, Department of Molecular Genetics and Gene Technology, Utrechtseweg 48, PO Box 360, 3700 AJ Zeist, The Netherlands

5 Department of Cell Biology, John Innes Centre, Colney Lane, Norwich NR4 7UH, UK
}

\begin{abstract}
A glucoamylase:: green fluorescent protein fusion (GLA::sGFP) was constructed which allows the green fluorescent protein to be used as an in vivo reporter of protein secretion in Aspergillus niger. Two secretory fusions were designed for secretion of GLA::sGFP which employed slightly different lengths of the glucoamylase protein (GLA499 and GLA514). Expression of GLA::sGFP revealed that fluorescence was localized in the hyphal cell walls and septa, and that fluorescence was most intense at hyphal apices. Extracellular GLA::sGFP was detectable by Western blotting only in the supernatant of young cultures grown in soya milk medium. In older cultures, acidification of the medium and induction of proteases were probably responsible for the loss of extracellular and cell wall fluorescence and the inability to detect GLA::sGFP by Western analysis. A strain containing the GLA: : sGFP construct was subjected to UV mutagenesis and survivors screened for mutations in the general secretory pathway. Three mutants were isolated that were unable to form a halo on either starch or gelatin medium. All three mutants grew poorly compared to the parental strain. Fluorescence microscopy revealed that for two of the mutants, GLA::sGFP accumulated intracellularly with no evidence of wall fluorescence, whereas for the third mutant, wall fluorescence was observed with no evidence of intracellular accumulation. These results indicate that the GLA::sGFP fusion constructs can be used as convenient fluorescent markers to study the dynamics of protein secretion in vivo and as a tool in the isolation of mutants in the general secretory pathway.
\end{abstract}

Keywords: Aspergillus niger, protein secretion, glucoamylase, green fluorescent protein $(\mathrm{GFP})$, heterologous protein production

\section{INTRODUCTION}

Filamentous fungi have a high capacity for secretion of extracellular enzymes. Members of the genera Aspergillus and Trichoderma have been reported to produce, under optimal fermentation conditions, $20 \mathrm{~g}$ glucoamylase $1^{-1}$ and $40 \mathrm{~g}$ cellulases $\mathrm{l}^{-1}$, respectively (Finkelstein, 1987; Durand et al., 1988). In addition, the GRAS

Abbreviations: ER, endoplasmic reticulum; GFP, green fluorescent protein; sGFP, synthetic GFP(S65T); GLA, glucoamylase.
(Generally Regarded As Safe, US Food and Drug Administration) status of many industrially exploited strains makes them attractive hosts for the production of heterologous proteins. In many cases however, yields of heterologous proteins rarely exceed more than a few milligrams per litre (Gouka et al., 1997a). Despite low levels of secreted heterologous proteins, high mRNA levels have been recorded in some cases, suggesting that bottlenecks exist at the post-transcriptional level, possibly within the secretory pathway (Jeenes et al., 1994; Nyyssönen \& Keränen, 1995; Gouka et al., 1996). The 
development of a gene fusion strategy, whereby a homologous, well-secreted protein is fused to the heterologous protein of interest, has been shown to help alleviate post-translational limitations, although levels of secreted protein are often still much lower than those obtained for homologous proteins (Ward et al., 1990; Contreras et al., 1991; Broekhuijsen et al., 1993; Archer et al., 1994; Gouka et al., 1997b).

In filamentous fungi, protein secretion is thought to occur at growing hyphal apices where released proteins can pass by 'bulk flow' through the newly synthesized cell wall (Wessels, 1994). Wösten et al. (1991) demonstrated indirectly that secretion was coupled to hyphal growth and that glucoamylase appeared to be secreted primarily at the apices of Aspergillus niger hyphae, although subapical localization of glucoamylase in $A$. niger (A. Keizer-Gunnink, personal communication) and lignin peroxidase in Phanerochaete chrysosporium (Moukha et al., 1993) has also been reported.

Green fluorescent protein (GFP) from the jellyfish Aequorea victoria has been used as a reporter for monitoring gene expression and protein localization studies in many organisms (Chalfie, 1995). Red-shifted variants of GFP have been developed, in which the excitation maximum peak is shifted to $490 \mathrm{~nm}$, resulting in much brighter fluorescence than the wild-type (Heim et al., 1995). A synthetic version of one of these variants, S65T (sGFP), was developed for use in plants (Chiu et al., 1996; Haas et al., 1996) and has been expressed successfully in a number of fungi, including Candida albicans, Aspergillus nidulans, Aureobasidium pullulans and Ustilago maydis, (Spellig et al., 1996; Cormack et al., 1997; Suelmann et al., 1997; van den Wymelenberg et al., 1997; Fernández-Ábalos et al., 1998; Siedenberg et al., 1999).

In this study, we describe the expression of a glucoamylase (GLA): :sGFP (GLA::sGFP) fusion protein in $A$. niger as an in vivo reporter of protein secretion in growing hyphae. The results demonstrate the use of GLA::sGFP fusion proteins as in vivo reporters of protein trafficking and secretion in A. niger and as a tool in the isolation of mutants in the general secretory pathway.

\section{METHODS}

Strains and plasmids. A. niger AB4.1 (van Hartingsveldt et al., 1987 ) is a pyrG mutant derived from A. niger N402. A. niger D15 is a mutant derived from a protease-deficient strain of AB1.13 (Mattern et al., 1992) which acidifies the culture medium far less (P. Punt, unpublished observation). An ile19 A. niger mutant was kindly provided by David Gems (John Innes Centre, Norwich, UK). The synthetic sgfp gene encoding the S65T variant of GFP (Chiu et al., 1996; Haas et al., 1996) was used in all constructs. Plasmids pMCB30 (FernándezAbalos et al., 1998) and pBluescript-sGFP-TyG-nos-hs (Sheen et al., 1995) both contained $s g f p$. Plasmid pIGF contains the $A$. niger glaA promoter and truncated glaA gene (equivalent to 499 amino acids, G499) and glaA terminator region (Archer et al., 1994). Plasmid pAN56-2 contains the glaA promoter region and truncated glaA (equivalent to 514 amino acids,
G514) and A. nidulans trpC termination sequences (EMBLZ32690). Plasmid pAB4.1 containing the A. niger pyrG gene (van Hartingsveldt et al., 1987) and plasmid pAN7.1 containing the bacterial hygromycin resistance marker (Punt et al., 1987; Punt \& van den Hondel, 1992) were used for selection purposes.

Growth and culture conditions. A. niger cytoplasmic sGFP and GLA514 fusion strains were grown on BenneH/Lasure media, whereas the GLA499 fusion strains were grown on Vogel's medium (Vogel, 1956) (modified by substitution of $10 \mathrm{~g}$ maltodextrin or glucose $\mathbf{1}^{-1}$ for sucrose), solidified with $1.5 \%(\mathrm{w} / \mathrm{v})$ agar when required. For microscopy, spores of the cytoplasmic sGFP and GLA514 fusion strains were adhered to coverslips and grown under a thin liquid layer in a Petri dish (Harris et al., 1994). A modified version of soya milk medium (MacKenzie et al., 1994) was also used. Media for A. niger pyrG strains contained $10 \mathrm{mM}$ uridine. Conidia for spore inocula were grown on potato dextrose agar (PDA), harvested after 5-6 d with $0 \cdot 1 \%(\mathrm{w} / \mathrm{v})$ Tween 20 and washed twice with distilled water. All cultures were grown at $30^{\circ} \mathrm{C}$ and agitated at 250 r.p.m. when necessary.

Construction of gene fusions and transformant strains. Molecular methods for plasmid isolation, restriction enzyme analysis, ligation of DNA fragments and transformation of Escherichia coli were essentially as described by Sambrook et al. (1989). Constructs are shown in Fig. 1. For the GLA499:: sGFP-encoding construct, a full-length 742 bp sgfp fragment was generated by PCR using pMCB30 as a template. Primers used were (1) 5'-CGATATCTAGAATGGTGGCAAGGGCGAGGA, and (2) 5'-TGACTTCTAGATTACTTGTACAGCTCGTCCA. The $s g f p$ fragments were digested and ligated into the $\mathrm{XbaI}$ cloning site of pIGF between the truncated glaA gene and the glaA terminator. The GLA514::sGFP-encoding gene fusion was generated by cloning $s g f p$ as an NcoI (blunt)-BamHI fragment from pBluescript-sGFP-TyG-nos-hs (Sheen et al., 1995) between the EheI and BglII (partial) sites of pAN 56-2 Not, resulting in the vector pAN56-2sGFP. For the GLA514::sGFP-HDEL-encoding gene fusion, pBluescript-sGFP-TyG-nos-hs (Sheen et al., 1995) was used as the template. Primers used were (1) reverse primer on pBluescript 5'-GGAAACAGCTATGACCATG, and (2) sGFP-HDEL-reverse primer 5'-CGGGATCCTTACAGCTCGTCGTGCTTGTACAGCTCGTCCATGCC. The 882 base pair sGFP-HDEL fragment was digested with $\mathrm{NcoI}$ and BamHI and cloned into pAN56-2 to give pAN562(sGFP-HDEL). All constructs were verified by sequencing. The cytoplasmic sGFP was constructed as described by Siedenberg et al. (1999).

For transformation experiments, A. niger cultures were grown for $18-20 \mathrm{~h}$ in Vogel's medium (supplemented with $10 \mathrm{mM}$ uridine for strain AB4.1). Protoplasts were prepared with $20 \mathrm{mg}$ Novozyme 234 (Novo Nordisk) (g wet wt mycelia) ${ }^{-1}$ and $s g f p$-containing constructs were co-transformed into $A$. niger AB4.1 with pAB4.1 and into A. niger N402 with pAN7.1 using polyethylene glycol as described previously (Punt \& van den Hondel, 1992). Transformants containing the $s g f p$ fusion constructs were purified and the presence of $s g f p$ was verified by Southern blotting (Southern, 1975) and colony PCR (van Zeijl et al., 1998).

Microscopy. Fluorescence microscopy with the A. niger cytoplasmic sGFP and GLA514 fusion strains was conducted using a Zeiss axioplan microscope. Standard FITC filters were used. Fixation of mycelia for electron microscopy was carried out overnight at room temperature with $2.5 \%(\mathrm{v} / \mathrm{v})$ glutaraldehyde in $0.05 \mathrm{M}$ sodium cacodylate with $0.05 \%(\mathrm{v} / \mathrm{v})$ 
Cytoplasmic sGFP

Pgla::sGFP

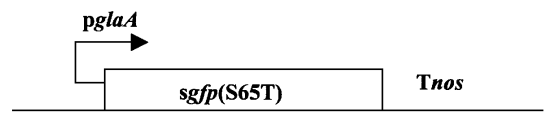

Secretory GLA::sGFP fusions Pgla-GLA499: :SGFP

Pgla-GLA514::sGFP
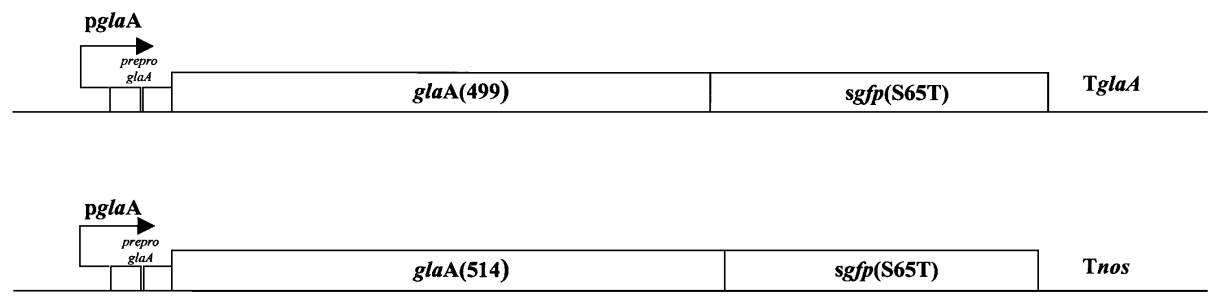

ER-targeted

GLA::sGFP-HDEL fusion

Pgla-GLA514::sGFP-HDEL

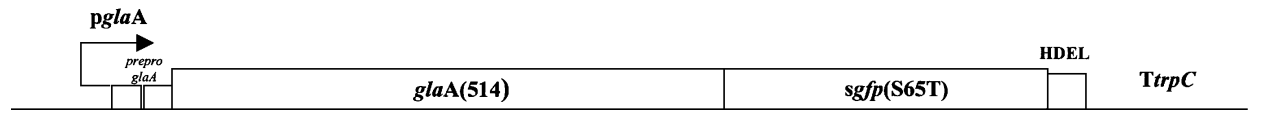

Fig. 1. Schematic representation of the GLA::sGFP fusion constructs. Four sGFP constructs were made, each using the promoter from the $A$. niger glaA gene. The cytoplasmic sGFP construct had no glucoamylase coding sequence. Two secretory GLA::sGFP constructs were made which differed in the lengths of the truncated gene (encoding either GLA499 or GLA514). The ER-targeted GLA::sGFP construct had a HDEL signal at the C-terminal end of the fusion protein. TglaA, Tnos and TtrpC represent the terminator regions of $A$. niger glaA, Zea mays nos or $A$. nidulans trpC genes, respectively.

Nonidet P40. Dehydration was achieved with an ethanol series with progressive cooling to $-35^{\circ} \mathrm{C}$. Fungal tissue was embedded in LR white resin containing $0.05 \%(\mathrm{w} / \mathrm{v})$ benzoin methyl ether in a low-temperature box and polymerization mediated by UV light at $-20^{\circ} \mathrm{C}$. Sections, on gold grids, were blocked with $1 \%(\mathrm{w} / \mathrm{v})$ acetylated BSA (Aurion BSA-C) with $0 \cdot 01 \%(\mathrm{v} / \mathrm{v})$ Tween 20 for $1 \mathrm{~h}$. Grids were incubated in a $1: 15$ dilution of anti-sGFP antibodies (Clontech polyclonal antisGFP) overnight at $4{ }^{\circ} \mathrm{C}$. After washing three times in PBS, sections were incubated in $10 \mathrm{~nm}$ gold-conjugated goat antirabbit antibody (Biocell) for $1 \mathrm{~h}$ at room temperature. Both primary and secondary antibodies were cross-absorbed using an acetone powder of $A$. niger at $10 \mathrm{mg} \mathrm{ml}^{-1}$ for $30 \mathrm{~min}$ just prior to use. After washing in PBS, sections were fixed in $1 \%$ glutaraldehyde in PBS for $15 \mathrm{~min}$ and washed four times in water before being stained with uranyl acetate/lead citrate and observed in a JEOL 1200EX electron microscope.

Analytical methods. Growth was measured by biomass dry weight, with mycelia filtered through filter papers (Whatman no. 1) and dried to constant weight. Extracellular culture supernatant samples were filtered through a $0 \cdot 2 \mu \mathrm{m}$ membrane and stored at $-20{ }^{\circ} \mathrm{C}$. For relative fluorescence measurements in liquid culture, $1.5 \mathrm{ml}$ samples were excited at $490 \mathrm{~nm}$ using a Hitachi 2000 fluorescence spectrophotometer with a $508 \mathrm{~nm}$ emission filter. Recombinant red-shifted GFP (Clontech) was used as a control. SDS-PAGE was conducted using standard protocols (Sambrook et al., 1989). Electroblotting of proteins onto nitrocellulose (Hybond-C; Amersham) was conducted as described by Towbin et al. (1979). Immunodetection of sGFP was achieved with a 1:500 dilution of rabbit anti-sGFP antibodies (Clontech), and of glucoamylase with a 1:5000 dilution of rabbit anti-glucoamylase antibodies (kindly provided by Novo Nordisk) using an anti-rabbit antibody peroxidase linked system (ECL; Amersham). To study proteolytic degradation of sGFP, $7 \mu$ g recombinant sGFP protein (Clontech) was incubated for up to $6 \mathrm{~h}$ with $140 \mu \mathrm{l}$ culture filtrates from the end of the exponential phase of A. niger
AB4.1 grown in soya milk or Vogel's medium. Samples were taken at regular intervals and subjected to Western blotting.

Mutagenesis and screening for mutants in the general secretory pathway. Aliquots $(20 \mathrm{ml})$ of a spore suspension $\left(1 \times 10^{7}\right.$ spores $\left.\mathrm{ml}^{-1}\right)$ of $A$. niger $\mathrm{N} 402$ containing the GLA499::sGFP construct was subjected to UV mutagenesis (UVP; model R-52G) for $40 \mathrm{~s}$, which killed between 95 and $99 \%$ of spores. Mutagenized spores were spread onto modified Vogel's agar medium (containing $0 \cdot 1 \%(\mathrm{w} / \mathrm{v})$ glucose and $0.05 \%(\mathrm{v} / \mathrm{v})$ Triton $\mathrm{X}-100)$ at a spore density sufficient to give rise to 30-50 colonies after incubation for $3 \mathrm{~d}$ at $25^{\circ} \mathrm{C}$. Triton $\mathrm{X}-100$ was included in the medium to restrict colony growth. Molten modified Vogel's starch medium [containing $1 \%(\mathrm{w} / \mathrm{v})$ corn starch] $(10 \mathrm{ml})$ was poured carefully over the colonies and plates were incubated at $42{ }^{\circ} \mathrm{C}$ for $24 \mathrm{~h}$. Previous studies had shown that non-mutagenized colonies would produce a visible halo in the starch-containing medium after between 6 and $14 \mathrm{~h}$. Colonies which did not form a halo after $24 \mathrm{~h}$ were subcultured and rescreened on starch-containing medium at both 25 and $42^{\circ} \mathrm{C}$. Spore suspensions or mycelial plugs ( $4 \mathrm{~mm}$ diam.) of mutants from the secondary screen were used to inoculate Vogel's gelatin medium [containing $1 \%$ glucose, $1 \%(\mathrm{w} / \mathrm{v})$ gelatin, $0.05 \%$ Triton X-100 and lacking ammonium sulphate) and incubated at 25 and $42{ }^{\circ} \mathrm{C}$ for 4 and $2 \mathrm{~d}$, respectively. Previous studies had shown that non-mutagenized colonies would produce a clearing zone around the colonies after $18-24$ and $6-14 \mathrm{~h}$ at 25 and $42^{\circ} \mathrm{C}$, respectively.

\section{RESULTS}

\section{Analysis of the expression and localization of GLA::sGFP protein fusions in $A$. niger}

For the construction of chimeric sGFP fusion proteins, synthetic GFP(S65T) (sGFP) was used which has been adapted for expression in animal and plant cells (Chiu et 

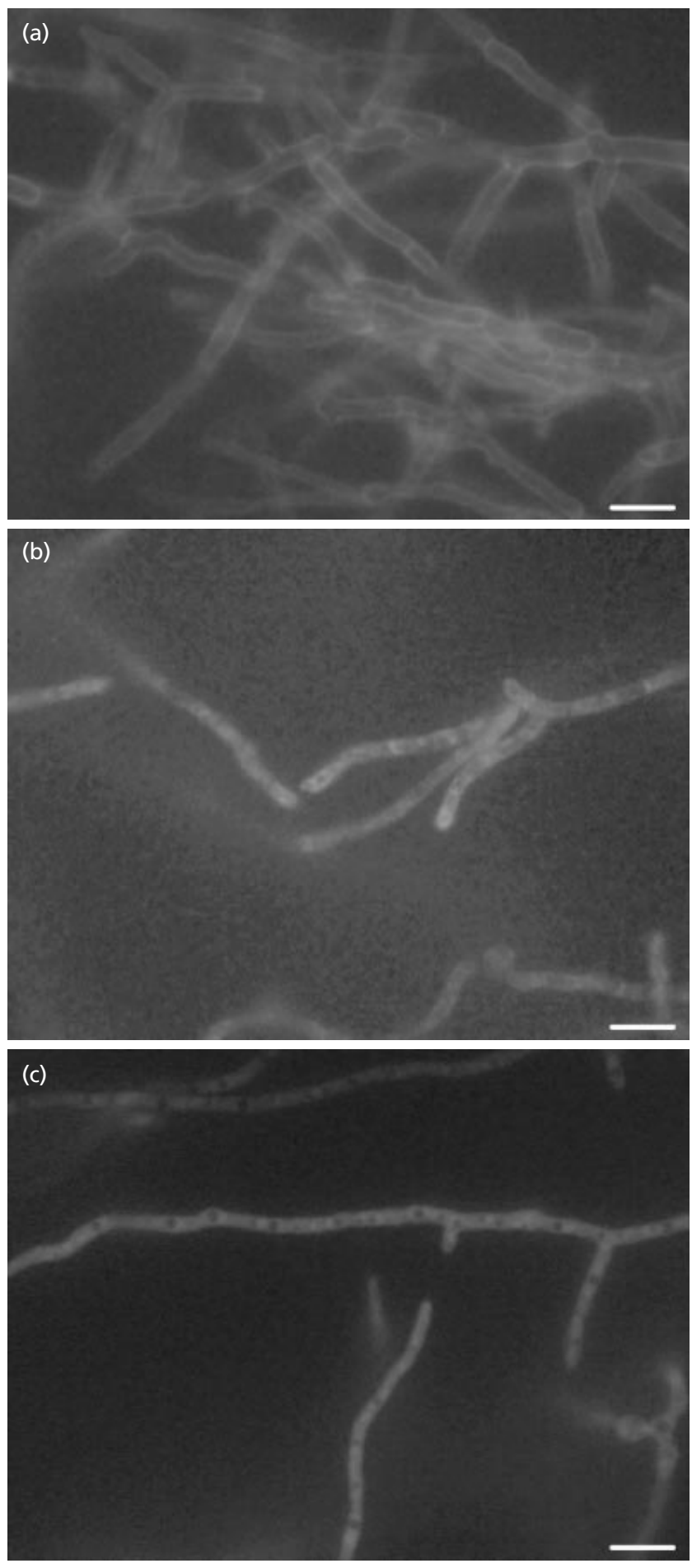

Fig. 2. Analysis of $A$. niger $A B 4.1$ transformants expressing sGFP fusion proteins. Hyphae of transformants expressing (a) the secretory construct G514::sGFP, (b) the ER-directed construct G514::sGFP-HDEL and (c) the cytoplasmic sGFP construct. Transformants were grown at $30{ }^{\circ} \mathrm{C}$ for $20 \mathrm{~h}$. Bar, $20 \mu \mathrm{m}$.

al., 1996; Haas et al., 1996), and has been successfully expressed in filamentous fungi. For the cytoplasmic expression of $g f p$ in $A$. niger, the $g f p$ gene was fused to the A. niger glaA promoter (Fig. 1). The glaA promoter is known to direct production of high levels of glucoamylase in the presence of starch, maltodextrin and glucose, and to be repressed when xylose is used as a carbon source (Fowler et al., 1990; Schrickx et al., 1993; Verdoes et al., 1994; Siedenberg et al., 1999). Analysis of $A$. niger transformants containing the $g f p$ gene by fluorescence microscopy showed high expression levels of cytoplasmic sGFP when grown on glucose. sGFP was present throughout the cytoplasm and appeared to be excluded from the vacuoles, which were visible as dark spots within hyphal compartments (Fig. 2c). Very low background fluorescence was observed in transformants that only contained the selectable marker (results not shown) or in medium with xylose as the sole carbon source, indicating that sGFP expression was still under control of the glaA promoter (Siedenberg et al., 1999).

To monitor protein secretion in vivo, the sGFP gene was fused to glaA. Two different constructs were made using either the coding sequence for the first 499 amino acids or the first 514 amino acids of glucoamylase (GLA499:: sGFP and GLA514:: sGFP, respectively; Fig. 1). Expression of both fusion proteins in $A$. niger resulted in similar patterns of localization. Most fluorescence was observed in the cell walls and in septa, indicating that both fusion proteins are secreted and at least partially retained within the cell wall (Fig. 2a). No significant intracellular fluorescence was observed and the pattern of fluorescence contrasted sharply to the granular intracellular fluorescence observed with the GLA : : sGFP-HDEL [endoplasmic reticulum (ER)-retention signal] strain (Fig. 2b) and the more homogeneous fluorescence observed in the cytoplasmic-sGFP-expressing transformant (Fig. 2c). Immunogold labelling of longitudinal sections of hyphae of the GLA::sGFPexpressing strain by scanning electron microscopy confirmed the presence of sGFP within the hyphal cell wall (Fig. 3). In addition, we were able to remove GLA::sGFP fusion protein from the cell wall using a mild SDS-extraction of intact mycelium $[0.05 \%$ SDS in $50 \mathrm{mM}$ sodium phosphate buffer $(\mathrm{pH} 7 \cdot 0)$ for $5 \mathrm{~min}$ at $95^{\circ} \mathrm{C}$. This treatment did not cause lysis of the mycelia as no glucose-6-phosphate dehydrogenase, a cytoplasmic protein, was detected on Western blots (results not shown).

\section{GLA::sGFP expression and localization in batch culture}

Initially in shake-flask cultures, GLA : :sGFP was visible as bright fluorescence in the cell walls and septa; however fluorescence was typically lost after 16-20 h growth (Fig. 4a). In contrast, intracellular fluorescence was still observed in the cytoplasmic sGFP strain (results not shown) and the GLA::sGFP-HDEL transformant (Fig. 4b). As GFP fluorescence is sensitive to low $\mathrm{pH}$ (Patterson et al., 1997), the rapid acidification of the medium in shake-flask cultures during the growth of $A$. niger probably accounts for the observed loss of fluorescence in the hyphal wall. Loss of fluorescence in 


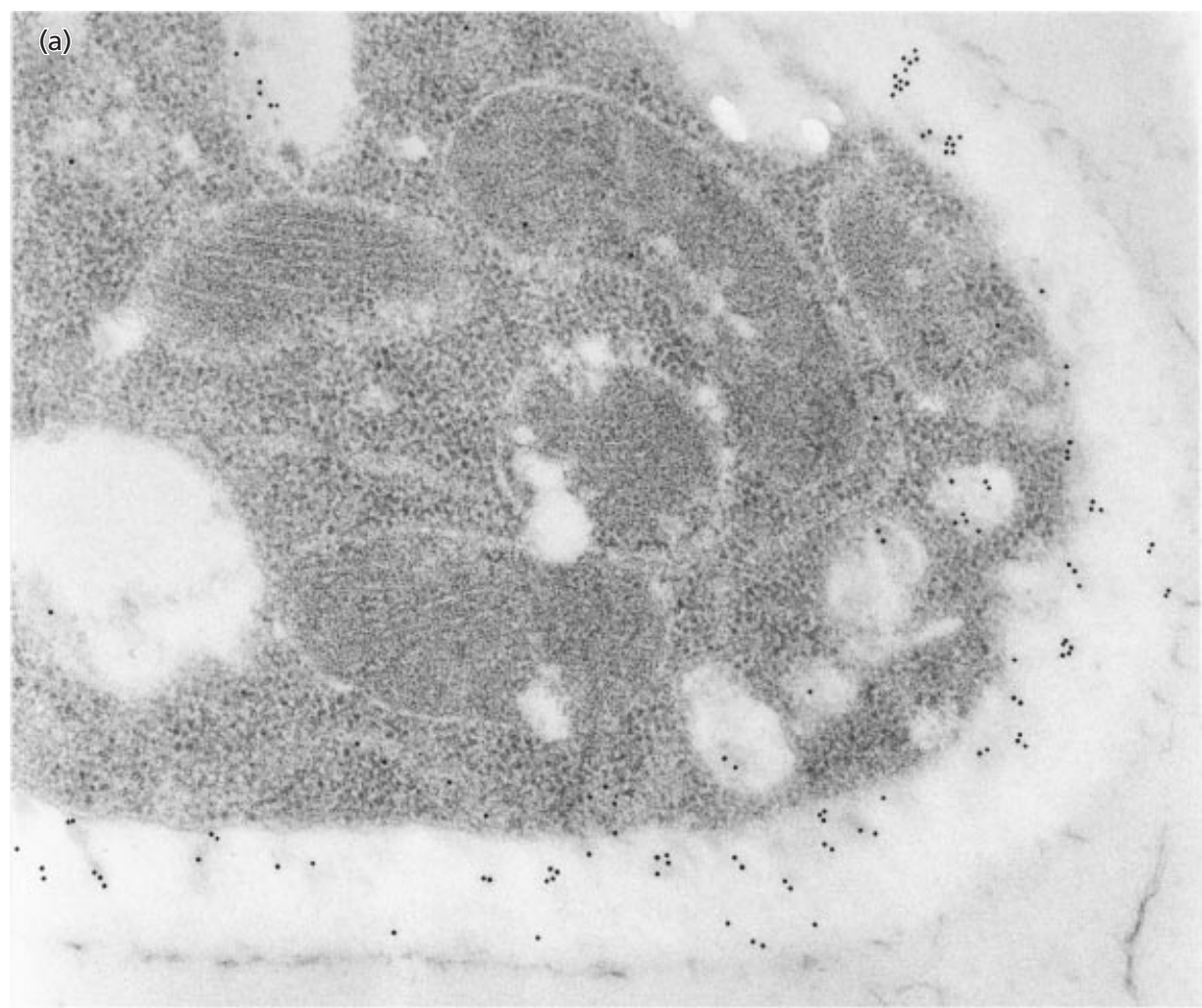

(b)

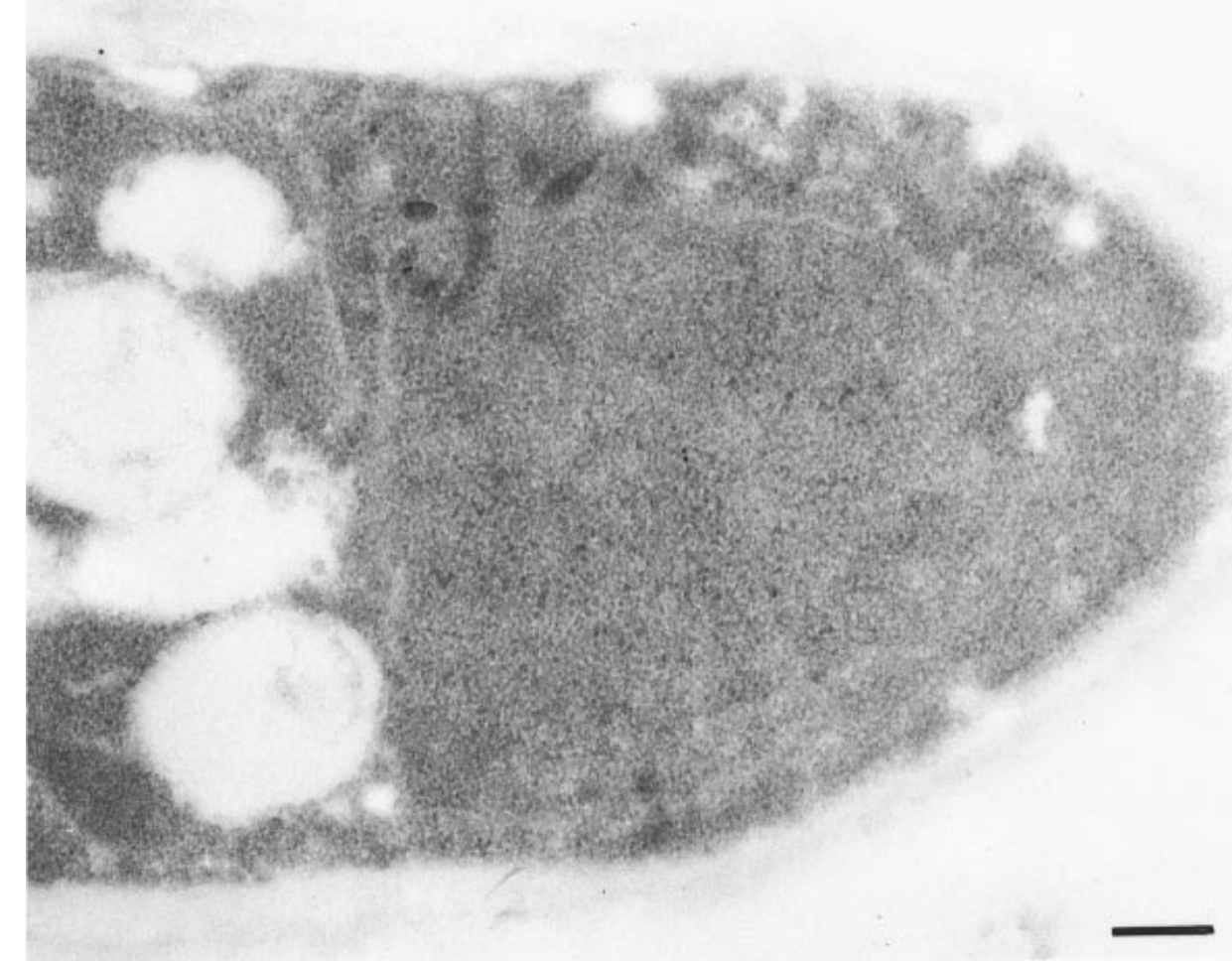

Fig. 3. Scanning electron micrographs of immuno-gold labelled longitudinal sections of hyphae of (a) A. niger AB4.1 transformed with the G499::sGFP construct and (b) untransformed A. niger (ile19). The presence of large organelles in the sections suggest that they are not at, but are close to, hyphal apices. Bar, $200 \mathrm{~nm}$. 

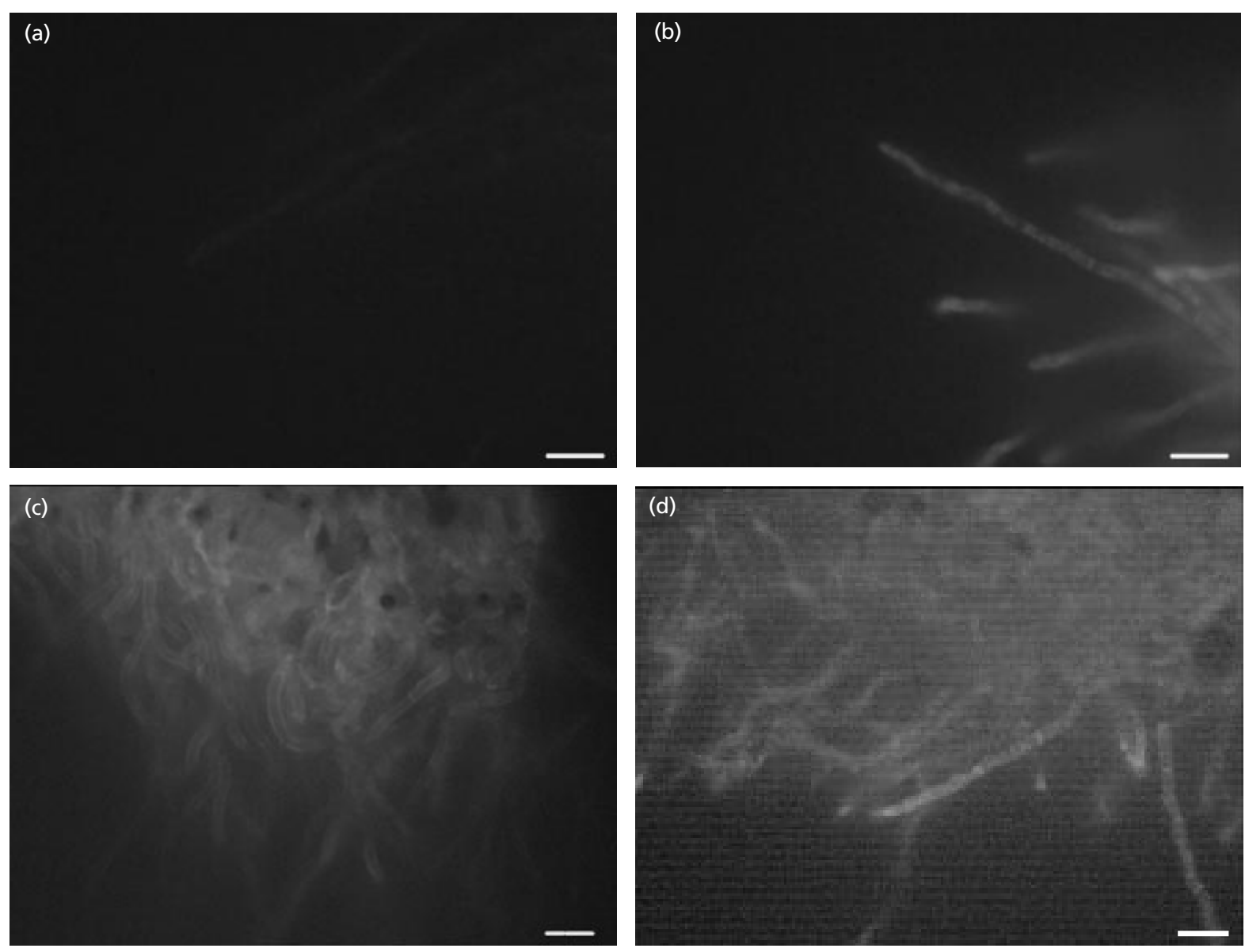

Fig. 4. $A$. niger $A B 4.1$ and $D 15$ transformants expressing sGFP fusion proteins in shake-flask culture. (a, b) $A$. niger $A B 4.1$ containing (a) the G514::sGFP construct and (b) the G514::sGFP-HDEL construct. (c, d) A. niger D15 containing (c) the G514::sGFP construct and (d) the G514::sGFP-HDEL construct. All strains were grown on minimal medium at $30^{\circ} \mathrm{C}$ with an initial $\mathrm{pH}$ of 6.0. Images were taken after $16 \mathrm{~h}$ growth. Bar, $20 \mu \mathrm{m}$.

the cell wall was not observed when the non-acidifying A. niger D15 mutant expressing GLA : :sGFP was grown in shake-flask culture (Fig. 4c, d). After 16 h growth, the $\mathrm{pH}$ of the culture medium of this transformant remained at the initial value of $6 \cdot 0$. The effect of extracellular $\mathrm{pH}$ on the fluorescence of sGFP in the hyphal wall could be further demonstrated by studying the effect of changing the extracellular $\mathrm{pH}$ on cell wall fluorescence. The cell walls of A. niger D15 GLA::sGFP were fluorescent when at $\mathrm{pH} 6.0$ but lost fluorescence over a period of 90 min when transferred to $\mathrm{pH} 3.5$ (Fig. 5a, b). As predicted, the intracellular fluorescence of A. niger D15 expressing GLA::sGFP-HDEL was not affected by changing the external pH (Fig. 5c, d).

\section{Secretion of GLA::sGFP takes place at the hyphal tips}

Newly synthesized GFP molecules need to be processed into their mature form, i.e. the chromophore, before being able to emit fluorescence. Although sGFP(S65T) has been shown to fold more rapidly than wild-type GFP, this may still take up to $45 \mathrm{~min}$ (Heim et al., 1995). When freshly grown mycelia were directly observed using the fluorescence microscope, a lower fluorescent signal was often observed in the hyphal apices compared to more subapical regions and septa. It is possible that the time required for chromophore formation is responsible for this observation. To overcome this problem, young germlings were held at a low temperature $\left(6^{\circ} \mathrm{C}\right)$ for at least $2 \mathrm{~h}$ before observations, to slow down protein secretion and to allow newly secreted sGFP to become fluorescent. In doing so, intense fluorescence was observed at most hyphal apices compared to subapical regions (Fig. 6a). Loss of fluorescence from the subapical hyphal wall was also observed after $28 \mathrm{~h}$ (Fig. $6 \mathrm{~b})$, probably due to the increased acidification of the medium.

\section{Localization of secreted GLA::sGFP fusion proteins}

To investigate whether the GLA::sGFP fusion protein could be detected in the culture medium, samples of culture media were taken at different times during growth in shake-flask cultures and analysed for the presence of sGFP by Western blotting and fluorescence spectrophotometry. Neither intact nor degraded 

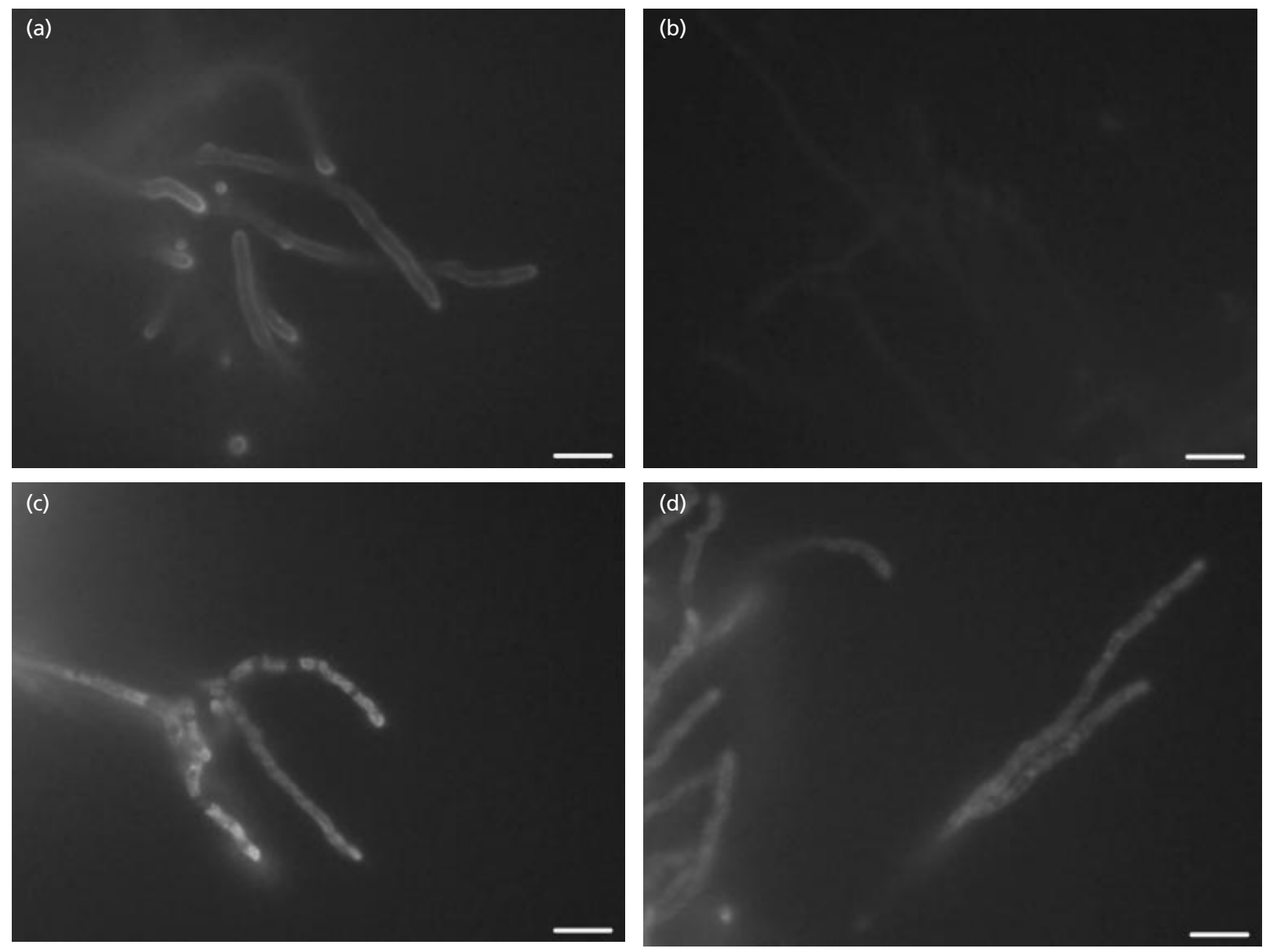

Fig. 5. Effect of ambient $\mathrm{pH}$ on extracellular GLA::sGFP fluorescence. (a, b) A. niger D15 transformed with the G514::sGFP construct incubated (a) in $0.9 \% \mathrm{NaCl} \mathrm{pH} 6.0$ or (b) after 90 min incubation in $0.9 \% \mathrm{NaCl}$ adjusted to pH $3.5 \mathrm{with} \mathrm{HCl}$. (c, d) A. niger D15 transformed with the G514::sGFP-HDEL construct incubated (c) at pH 6.0 or (d) at pH 3.5. Bar, $20 \mu \mathrm{m}$.

GLA::sGFP could be detected at any point during growth on minimal medium. This suggests that the GLA::sGFP fusion protein is either efficiently retained within the cell wall or is rapidly degraded on release into the culture medium. In contrast, extracellular fluorescence was detected when the GLA::sGFP transformant was grown in shake-flask cultures in soya milk medium (Fig. 7a). Fluorescence was highest $2 \mathrm{~d}$ after inoculation and thereafter declined steadily until after $8 \mathrm{~d}$ no significant fluorescence was detectable.

Western analysis of medium samples with anti-sGFP antibody after $4 \mathrm{~d}$ growth on soya milk medium revealed the presence of a single protein species with a molecular mass of approximately $102 \mathrm{kDa}$, the predicted size of the GLA::sGFP fusion protein (Fig. 7bi, lane 1) or the presence of both a $102 \mathrm{kDa}$ and a $27 \mathrm{kDa}$ protein (7bii, right panel, lane 1). Detection of a $102 \mathrm{kDa}$ protein using anti-glucoamylase (Fig. 7bii, left panel, lane 1), which was absent in the parental strain (Fig. 7bii, left panel, lane 2), confirmed that the medium contained a GLA : : sGFP fusion protein. After $6 \mathrm{~d}$ growth, no intact GLA : :sGFP fusion protein could be detected, but some degraded sGFP was still present (Fig. 7bi, lane 2). The size of this degradation product, with an apparent molecular mass of $27 \mathrm{kDa}$, the predicted size of sGFP, suggests that proteolytic cleavage occurred close to the linker region between the glucoamylase and sGFP. Beyond $6 \mathrm{~d}$, neither GLA : :sGFP nor sGFP could be detected (Fig. 7bi, lanes 3 and 4 ) indicating that initial cleavage of the GLA : :sGFP fusion protein was followed by subsequent degradation of sGFP, probably due to proteases present in the culture medium. To confirm that proteases present in the culture medium were capable of degrading sGFP, medium from cultures of $A$. niger AB4.1 grown on defined and soya milk medium were spiked with recombinant sGFP and analysed by Western blotting over a period of $60 \mathrm{~min}$. Recombinant sGFP was shown to be more rapidly degraded in culture filtrates obtained from A. niger AB4.1 grown in minimal medium compared to that from soya milk medium (Fig. 8).

\section{Isolation of mutants in the general secretory pathway}

A total of approximately 5000 colonies from UVmutagenized spores $(95-99 \%$ kill) of a transformant of 

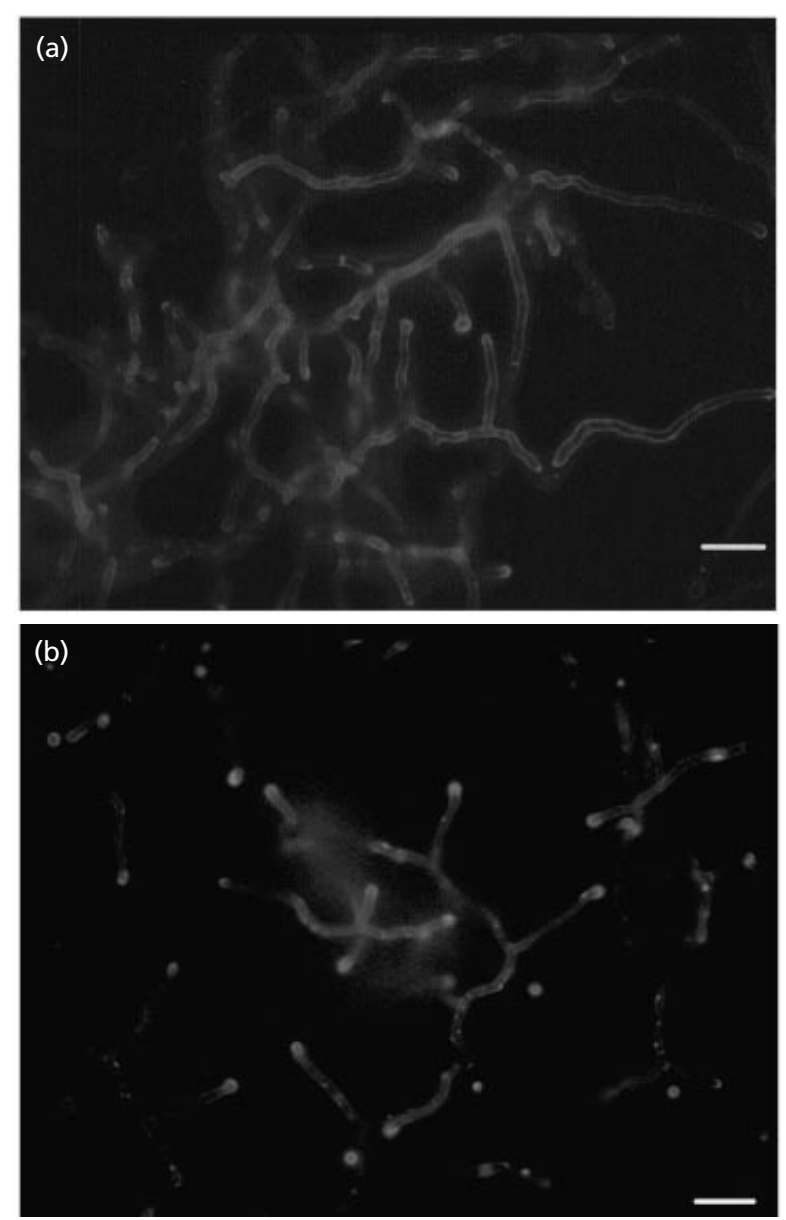

Fig. 6. Secretion occurs at the hyphal tips. Young germlings of $A$. niger AB4.1 G514::sGFP grown for (a) $20 \mathrm{~h}$ and (b) $28 \mathrm{~h}$ showing apical localization and loss of subapical wall fluorescence. Bar, $20 \mu \mathrm{m}$.

A. niger N402 expressing the GLA499::sGFP fusion protein were screened for defects in the general secretory pathway. Twenty-nine colonies were recovered which were unable to form a clearing zone on starch plates after $24 \mathrm{~h}$ at $42^{\circ} \mathrm{C}$. None of the colonies isolated produced a clearing zone on starch plates at $25^{\circ} \mathrm{C}$. When screened on gelatin medium, 10 putative general secretory pathway ( $g s p)$ mutants were isolated which were unable to form a clearing zone on gelatincontaining medium at either 25 or $42{ }^{\circ} \mathrm{C}$. Seven of these putative general secretory mutants were found to grow at a similar rate to the parental strain but with reduced sporulation (results not shown). Examination of these mutants revealed fluorescence localized in the walls and septa with no evidence of intracellular accumulation. The three remaining mutants ( $g s p 26,29$ and 31) all grew more slowly than the parental strain, displayed abnormally wide and swollen hyphae and lacked or had reduced levels of sporulation (results not shown). On examination under fluorescence microscopy, gsp 26 and 29 displayed intracellular accumulation of GLA : :sGFP with no fluorescence visible in either the cell walls or septa (Fig. 9). However, gsp 31 displayed a pattern of fluorescence similar to the parental strain with no intracellular accumulation and fluorescence present in both the cell walls and septa (results not shown).

\section{DISCUSSION}

A. niger is used commercially in the production of a wide range of secreted enzymes and is being developed as a host for the secretion of heterologous enzymes (Archer \& Peberdy, 1997; Gouka et al., 1997a). Despite the biotechnological importance of protein secretion in filamentous fungi, details of the secretory pathway are largely unknown. Much of our current knowledge regarding protein secretion has come from the study of temperature-sensitive secretion mutants in the yeast Saccharomyces cerevisiae. Identification of several homologues in other eukaryotes, including A. niger (Veldhuisen et al., 1997), indicates that the process of protein secretion is highly conserved. It is a reasonable assumption therefore, that protein secretion in yeasts and filamentous fungi will share many features. However, the biological and morphological differences between these two groups suggest that additional proteins may be involved in the process of protein secretion in the fungal mycelium. This has been highlighted recently by the identification of an annexin homologue in Neurospora crassa which shares homology to the annexin gene family in higher eukaryotes but appears to be absent in S. cerevisiae (Braun et al., 1998).

In a series of gene fusions we replaced the starch-binding domain of glucoamylase with sGFP to create fluorescent markers for the study of the secretion process in $A$. niger. Three glucoamylase sGFP fusions were made. Two of them were designed for secretion of the fusion protein and employed two different lengths of the glucoamylase protein (GLA499 and GLA514), although both constructs lacked the starch-binding domain. This approach has been used successfully to secrete heterologous proteins in both cases. The third construct included a C-terminal HDEL motif designed to retain the fusion protein within the lumen of the ER. The different lengths of glucoamylase in the secretory fusions were found to have no significant effect as both GLA499::sGFP and GLA514::sGFP produced the same patterns of fluorescence in A. niger, and were distinct from that of the ER-retained GLA514::sGFP-HDEL and the cytoplasmic-sGFP-containing strains. In young mycelia expressing the GLA::sGFP fusion protein, bright fluorescence was observed in the hyphal walls indicating that the fusion protein was secreted, but retained within the cell wall. The presence of the fusion protein in the cell wall was confirmed by immuno-gold labelling. Retention of extracellular proteins in the hyphal wall has been reported previously for glucose oxidase in A. niger (Witteveen et al., 1992) and invertase in N. crassa (Trevithick \& Metezenberg, 1966) and for a variety of secreted proteins in S. cerevisiae (de Nobel \& Barnett, 1991). Using sGFP, we were able to directly observe in vivo the presence of the fusion protein within the cell wall, which would have been difficult based 
(a)
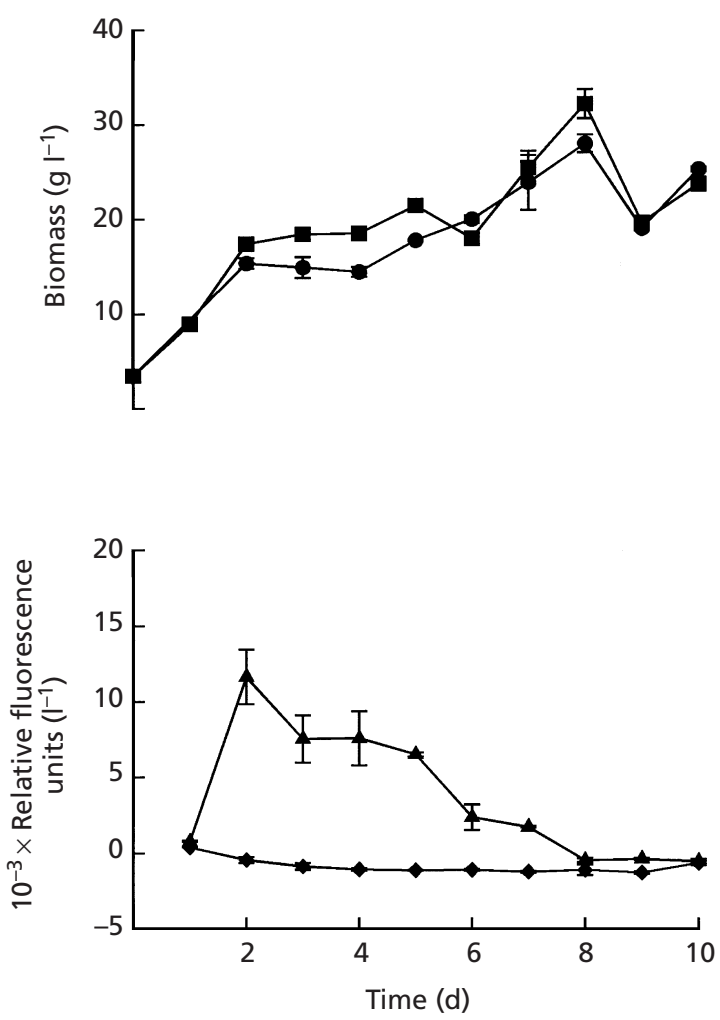

(b)

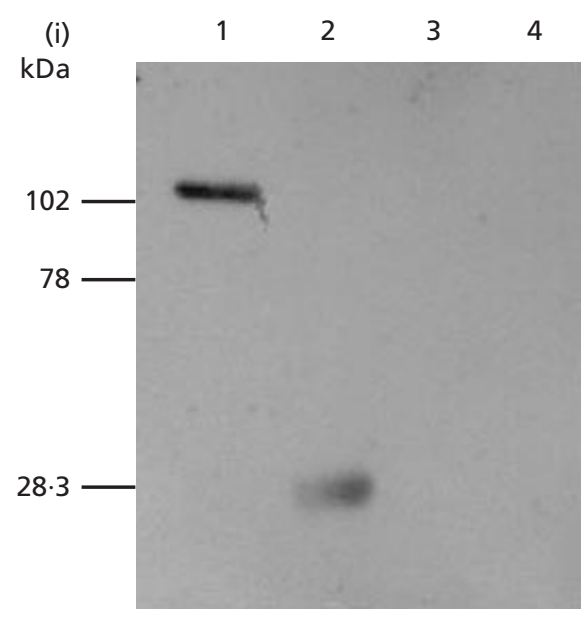

Anti-sGFP

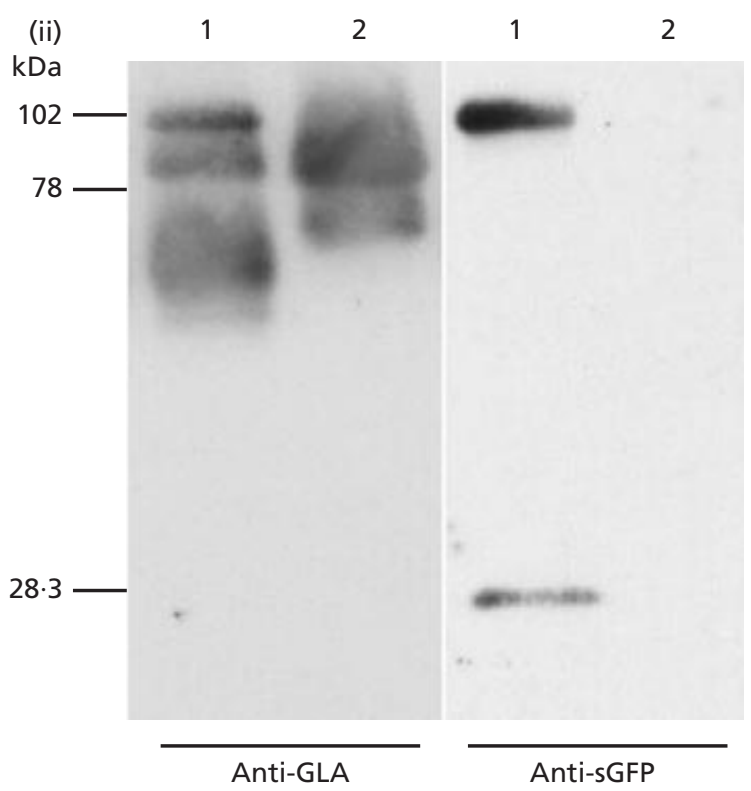

Fig. 7. (a) Growth of untransformed A. niger AB4.1 ( $\mathbf{a})$ and G499::sGFP (O) on soya milk medium containing $1 \%$ (w/v) maltodextrin for $10 \mathrm{~d}$, and the relative fluorescence of extracellular culture supernatant samples from $A B 4.1(\diamond)$ and G499::sGFP ( $\boldsymbol{\Delta})$. (b) Western blot analysis (i) using anti-sGFP antibodies of extracellular culture supernatant samples from A. niger AB4.1 G499::sGFP grown on soya milk medium for 4, 6, 8 and $10 \mathrm{~d}$ (lanes 1, 2, 3 and 4, respectively) and showing the GLA::sGFP fusion protein and (ii) using anti-glucoamylase (left panel) and anti-sGFP (right panel) antibodies on samples of culture filtrate from A. niger G499::sGFP (lane 1) and AB4.1 (lane 2) after $4 \mathrm{~d}$ growth on soya milk medium, demonstrating that the protein band with the highest molecular mass is the GLA::sGFP fusion protein.

solely on Western analysis. We developed a simple extraction method that released the fusion protein from the cell wall. It is likely that in previous studies in which glucoamylase-gene fusions have been used for heterologous protein secretion, cell wall localization was not recognized because the extraction method used did not discriminate between cell-wall-bound and intracellular proteins (Ward et al., 1990; Broekhuijsen et al., 1993; Archer et al., 1994; Gouka et al., 1997b).
The more intense fluorescence observed at hyphal apices supports the hypothesis that secretion of the fusion protein takes place at the hyphal tips (Wösten et al., 1991). However, as subapical regions of the cell wall were also fluorescent it appears that at least some of the GLA : :sGFP fusion protein is retained in the hyphal wall following secretion at the hyphal apex. Unexpectedly, septa were also brightly fluorescent, indicating the presence of GLA::sGFP fusion protein. Since the 


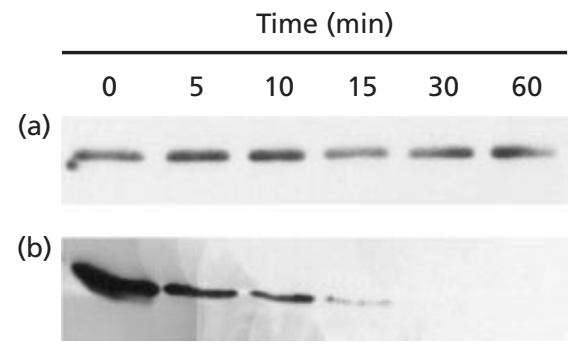

Fig. 8. Western blot analysis of SGFP degradation in $A$. niger culture filtrates. Recombinant sGFP was added to samples of culture filtrate from $A$. niger AB4.1 grown in soya milk medium (a) and Vogel's medium (b) and incubated for up to $60 \mathrm{~min}$ at $30^{\circ} \mathrm{C}$.
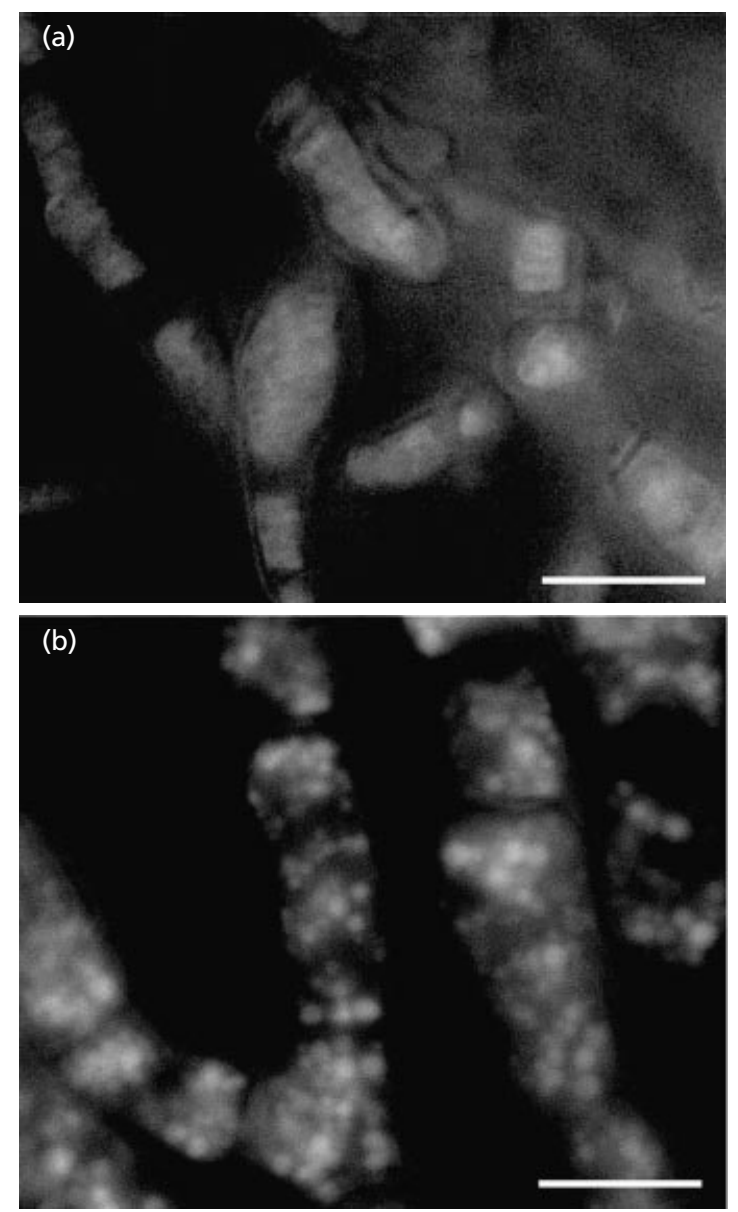

Fig. 9. Accumulation of intracellular fluorescence in strains gsp 26 (a) and gsp 29 (b) visualized after $36 \mathrm{~h}$ growth on Vogel's medium at $25^{\circ} \mathrm{C}$. Bar, $20 \mu \mathrm{m}$.

formation of septa takes place independently of apical growth, the question arises of how septa become fluorescent. One explanation might be that the GLA : : sGFP fusion protein in the cell wall is trapped but freely diffusible within the extracellular matrix. Alternatively, the GLA::sGFP fusion protein might be secreted during the formation of the septum. It is also possible that not all the secretion of the fusion protein is correlated with cell growth and that secretion also occurs in subapical cells without cell wall expansion. The effect of extracellular $\mathrm{pH}$ on fluorescence of the GLA::sGFP-expressing strain compared to the GLA : :sGFP-HDEL strain also provides further evidence for the extracellular localization of GLA::sGFP in the hyphal wall. Fluorescence of GFP has been shown to be sensitive to low $\mathrm{pH}$, and below $\mathrm{pH} 5.0$ loss of fluorescence may be irreversible (Kneen et al., 1998). The extracellular $\mathrm{pH}$ values of media of shake-flask cultures of $A$. niger have been shown to decrease to as low as $2 \cdot 0$ during growth (Archer et al., 1990). Low $\mathrm{pH}$ induces the production of proteases that are known to affect yields of heterologous proteins (Archer \& Peberdy, 1997; Gouka et al., 1997a; van den Homberg et al., 1997). Extracellular proteases probably account for the degradation of the GLA : :sGFP fusion proteins in the culture supernatant, even in soya milk medium where degradation of sGFP was found to occur at a slower rate than in defined medium. Cleavage of the GLA : :sGFP fusion protein appeared to occur initially within the linker region between the glucoamylase and sGFP as cleaved sGFP with an apparent molecular mass of $27 \mathrm{kDa}$ (the expected molecular mass for intact sGFP) was detected by Western analysis after $4 \mathrm{~d}$ growth in soya milk medium. Cleavage of the glucoamylase fusion protein at or near to the fusion junction has been reported for other heterologous proteins, even in the absence of a recognized processing site (Roberts et al., 1992). Further degradation of sGFP in the supernatant was indicated by the loss of detectable amounts of sGFP after $6 \mathrm{~d}$. The D15 mutant, which has a reduced ability to acidify the medium, was able to sustain extracellular wall fluorescence for longer than AB4.1. The data suggest that the GLA::sGFP fusion constructs can be used to monitor protein secretion in fermenters as long as the $\mathrm{pH}$ is held above $\mathrm{pH} 6.0$. It may also be possible to use the GLA : :sGFP-expressing strain to screen for additional protease-deficient mutants. Taken together, the results indicate that in young mycelia the GLA::sGFP fusion protein is primarily secreted at hyphal tips but partly retained within the cell wall, resulting in wall fluorescence. In older mycelia, extracellular wall fluorescence is lost as a result of the acidification of the culture medium and proteolytic degradation, possibly by acidinduced proteases.

To isolate potential mutants in the general secretory pathway, we developed a two-step screening procedure. Initially, mutants were isolated which were unable to degrade starch on plates and, subsequently, these were screened for their ability to degrade gelatin. It was assumed that mutants unable to degrade either of these substrates were more likely to be affected in the general secretory pathway. As general secretory pathway mutants may lead to a lethal phenotype, screening was initially performed at $42{ }^{\circ} \mathrm{C}$ on colonies that had been grown for $3 \mathrm{~d}$ at $25^{\circ} \mathrm{C}$ so that temperature-sensitive mutants could be selected. However, none of the 
mutants isolated from either the first starch plate screen or the subsequent gelatin plate screen displayed temperature sensitivity, i.e. the inability to degrade either substrate was displayed at both 25 and $42^{\circ} \mathrm{C}$. Of the 10 putative general secretory mutants isolated, 7 appeared to grow at the same rate as the parental strain but all showed reduced sporulation. None of these mutants when examined by fluorescence microscopy showed intracellular accumulation and all had fusion protein present in the walls and septa. These mutants were therefore disregarded. The lack of halo formation on starch and gelatin media may reflect a reduction in the overall ability of these strains to secrete proteins, resulting in delayed halo formation compared to the parent strain rather than a block in secretion per se. The remaining three putative general secretory pathway mutants all displayed poor growth at both 25 and $42{ }^{\circ} \mathrm{C}$ compared to the parental strain, a complete loss of sporulation and abnormal hyphal morphology. When examined under fluorescence microscopy, two mutants (gsp 26 and 29) displayed intracellular accumulation of GLA::sGFP fusion protein with no detectable fluorescence in the walls or septa. The third mutant (gsp 31) showed no accumulation and fluorescence in the wall or septa and was disregarded. The pattern of accumulation of GLA : :sGFP fusion protein in gsp 26 and 29 differed significantly from each other. In gsp 26 (Fig. 9a), fluorescence was diffuse and evenly located throughout the hyphae, whereas in $g s p 29$ (Fig. 9b), accumulation in circular bodies ranging in size from approximately 0.5 to $2 \mu \mathrm{m}$ diameter could clearly be seen. Thus, for both $g s p$ 26 and 29 , preliminary evidence strongly suggests the presence of defects in the general secretory pathway, leading to intracellular accumulation, and that these defects are likely to be affecting different points within the pathway. Further characterization of both gsp 26 and 29 is currently being undertaken to identify the sites at which accumulation occurs as well as examining the effects of inhibitors of secretion on the dynamics and organization of the secretory pathway. Thus the GLA : : sGFP constructs allow the direct visualization of protein secretion and localization in vivo in growing hyphae and have proved invaluable in the characterization of secretory mutants, allowing a quick and reliable method for confirming blocks in the secretory pathway and providing additional visual information on the sites of accumulation within the hyphae.

\section{ACKNOWLEDGEMENTS}

We would like to thank Jen Sheen for sGFP(S65T), Roy Montijn for help in the analysis of transformants and Gerda Lamers for assistance with the microscopical techniques.

The work carried out in the UK was funded by a BBSRC studentship to C.G. and a scholarship from the Pasteur Institute of Iran to V.K.

\section{REFERENCES}

Archer, D. B. \& Peberdy, J. F. (1997). The molecular biology of secreted enzyme production by fungi. Crit Rev Biotechnol 17, 273-306.
Archer, D. B., Roberts, I. N. \& MacKenzie, D. A. (1990). Heterologous protein secretion from Aspergillus niger in phosphatebuffered batch culture. Appl Microbiol Biotechnol 34, 313-315.

Archer, D. B., Jeenes, D. J. \& MacKenzie, D. A. (1994). Strategies for improving heterologous protein production from filamentous fungi. Antonie Leeuwenhoek 65, 245-250.

Braun, E. L., Kang, S. C., Nelson, M. A. \& Natvig, D. O. (1998). Identification of the first fungal annexin: analysis of annexin gene duplications and implications for eukaryotic evolution. $J \mathrm{Mol}$ Evol 47, 531-543.

Broekhuijsen, M. P., Mattern, I. E., Contreras, R., Kinghorn, J. R. \& van den Hondel, C. A. M. J. J. (1993). Secretion of heterologous proteins by Aspergillus niger: production of active human interleukin-6 in a protease-deficient mutant by KEX2-like processing of a glucoamylase-hIL6 fusion protein. J Biotechnol 31, 135-145.

Chalfie, M. (1995). Green fluorescent protein. Photochem Photobiol 62, 651-656.

Chiu, W.-L., Niwa, Y., Zeng, W., Hirano, T., Kobayashi, H. \& Sheen, J. (1996). Engineered GFP as a vital reporter in plants. Curr Biol 6, 325-330.

Contreras, R., Carrez, D., Kinghorn, J. R., van den Hondel, C. A. M. J. J. \& Fiers, W. (1991). Efficient KEX2-like processing of a glucoamylase-interleukin-6 fusion protein by Aspergillus nidulans and secretion of mature interleukin-6. Biotechnology $\mathbf{9}$, 378-381.

Cormack, B. P., Bertram, G., Egerton, M., Gow, N. A. R., Falkow, S. \& Brown, A. J. P. (1997). Yeast-enhanced green fluorescent protein $(\mathrm{yEGFP})$ : a reporter of gene expression in Candida albicans. Microbiology 143, 303-311.

Durand, H., Clanet, M. \& Tiraby, G. (1988). Genetic improvement of Trichoderma reesei for large scale cellulase production. Enzyme Microb Technol 10, 341-345.

Fernández-Ábalos, J. M., Fox, H., Pitt, C., Wells, B. \& Doonan, J. H. (1998). Plant-adapted green fluorescent protein is a versatile vital reporter for gene expression, protein localization and mitosis in the filamentous fungus Aspergillus nidulans. Mol Microbiol 27, 121-130.

Finkelstein, D. B. (1987). Improvement of enzyme production in Aspergillus. Antonie Leeuwenhoek 53, 349-352.

Fowler, T., Berka, R. M. \& Ward, M. (1990). Regulation of the glaA gene in Aspergillus niger. Curr Genet 18, 537-545.

Gouka, R. J., Punt, P. J., Hessing, J. G. M. \& van den Hondel, C. A. M. J. J. (1996). Analysis of heterologous protein production in defined recombinant Aspergillus awamori strains. Appl Environ Microbiol 62, 1951-1957.

Gouka, R. J., Punt, P. J. \& van den Hondel, C. A. M. J. J. (1997a). Efficient production of secreted proteins by Aspergillus: progress, limitations and prospects. Appl Microbiol Biotechnol 47, 1-11.

Gouka, R. J., Punt, P. J. \& van den Hondel, C. A. M. J. J. (1997b). Glucoamylase gene fusions alleviate limitations for protein production in Aspergillus awamori at the transcriptional and (post) translational levels. Appl Environ Microbiol 63, 488-497.

Haas, J., Park, E.-C. \& Seed, B. (1996). Codon usage limitation in the expression of HIV-1 envelope glycoprotein. Curr Biol 6, 315-324.

Harris, S. D., Morrell, J. L. \& Hamer, J. E. (1994). Identification and characterization of Aspergillus nidulans mutants defective in cytokinesis. Genetics 136, 517-532.

van Hartingsveldt, W., Mattern, I. E., van Zeijl, C. M. J., Pouwels, P. H. \& van den Hondel, C. A. M. J. J. (1987). Development of a 
homologous transformation system for Aspergillus niger based on the pyrG gene. Mol Gen Genet 206, 71-75.

van den Homberg, J.P. T. W., van de Vondervoort, P. J. I., Fraissinet-Tachet, L. \& Visser, J. (1997). Aspergillus as a host for heterologous protein production, the problem of proteases. Trends Biotechnol 15, 256-263.

Heim, R., Cubitt, A. B. \& Tsien, R. Y. (1995). Improved green fluorescence. Nature 373, 663-664.

Jeenes, D. J., MacKenzie, D. A. \& Archer, D. B. (1994). Transcriptional and post-translational events affect the production of secreted hen egg white lysozyme by Aspergillus niger. Transgenic Res 3, 297-303.

Kneen, M., Farinas, J., Li, Y. \& Verkman, A. S. (1998). Green fluorescent protein as a noninvasive intracellular $\mathrm{pH}$ indicator. Biophys J 74, 1591-1599.

MacKenzie, D. A., Gendron, L. C. G., Jeenes, D. J. \& Archer, D. B. (1994). Physiological optimization of secreted protein production by Aspergillus niger. Enzyme Microb Technol 16, 276-280.

Mattern, I. E., van Noort, J. M., van den Berg, P., Roberts, I. N., Archer, D. B. \& van den Hondel, C. A. M. J. J. (1992). Isolation and characterization of mutants of Aspergillus niger deficient in extacellular proteases. Mol Gen Genet 234, 332-336.

Moukha, S. M., Wösten, H. A. B., Asther, M. \& Wessels, J. G. H. (1993). In situ localization of the secretion of lignin peroxidases in colonies of Phanerochaete chrysosporium using a sandwiched mode of culture. J Gen Microbiol 139, 969-978.

de Nobel, J. G. \& Barnett, J. A. (1991). Passage of molecules through yeast cell walls - a brief essay review. Yeast 7, 313-323.

Nyyssönen, E. \& Keränen, S. (1995). Multiple roles of the cellulase $\mathrm{CBHI}$ in enhancing production of fusion antibodies by the filamentous fungus Trichoderma reesei. Curr Genet 28, 71-79.

Patterson, G. H., Knobel, S. M., Sharif, W. D., Kain, S. R. \& Piston, D. W. (1997). Use of the green fluorescent protein and its mutants in quantitative fluorescence microscopy. Biophys J 73, 2782-2790.

Punt, P. J., Oliver, R. P., Dingemanse, M. A., Pouwels, P. H. \& van den Hondel, C. A. M. J. J. (1987). Transformation of filamentous fungi based on the hygromycin B resistance marker from Escherichia coli. Gene 56, 117-124.

Punt, P. J. \& van den Hondel, C. A. M. J. J. (1992). Transformation of filamentous fungi based on hygromycin B and phleomycin resistance markers. Methods Enzymol 216, 447-457.

Roberts, I. N., Jeenes, D. J., MacKenzie, D. A., Wilkinson, A. P., Sumner, I. G. \& Archer, D. B. (1992). Heterologous gene expression in Aspergillus niger, a glucoamylase-porcine pancreatic prophospholipase A2 fusion protein is secreted and processed to yield mature enzyme. Gene 122, 155-161.

Sambrook, J., Fritsch, E. F. \& Maniatis, T. (1989). Molecular Cloning: a Laboratory Manual, 2nd edn. Cold Spring Harbor, NY: Cold Spring Harbor Laboratory.

Schrickx, J. M., Krave, A. S., Verdoes, J. C. \& van den Hondel, C. A. M. J. J. (1993). Growth and product formation in chemostat and recycling cultures by Aspergillus niger N402 and a glucoamylase overproducing transformant, provided by multiple copies of the glaA gene. J Gen Microbiol 139, 2801-2810.

Sheen, J., Hwang, S., Niwa, Y., Kobayashi, H. \& Galbraith, D. W. (1995). Green-fluorescent protein as a new vital marker in plant cells. Plant J 8, 777-784.
Siedenberg, D., Mestric, S., Ganzlin, M., Schmidt, M., Punt, P. J., van den Hondel, C. A. M. J. J. \& Rinas, U. (1999). GlaA promoter controlled production of a mutant green fluorescent protein (S65T) by recombinant Aspergillus niger during growth on defined medium in batch and fed-batch cultures. Biotechnol Prog $15,43-50$.

Southern, E. M. (1975). Detection of specific sequences among DNA fragments separated by gel electrophoresis. J Mol Biol 98, 503-517.

Spellig, T., Bottin, A. \& Kahmann, R. (1996). Green fluorescent protein (GFP) as a new vital marker in the phytopathogenic fungus Ustilago maydis. Mol Gen Genet 252, 503-509.

Suelmann, R., Sievers, N. \& Fischer, R. (1997). Nuclear traffic in fungal hyphae: in vivo study of nuclear migration and positioning in Aspergillus nidulans. Mol Microbiol 25, 757-769.

Towbin, H., Staehelin, T. \& Gordon, J. (1979). Electrophoretic transfer of proteins from polyacrylamide gels to nitrocellulose sheets: procedure and some applications. Proc Natl Acad Sci USA 76, 4350-4354.

Trevithick, J. R. \& Metezenberg, R. L. (1966). Molecular sieving by Neurospora crassa cell walls during secretion of invertase isoenzymes. J Bacteriol 92, 1010-1015.

Veldhuisen, G., Saloheimo, M., Fiers, M. A., Punt, P. J., Contreras, R., Penttila, M. \& van den Hondel, C. A. M. J. J. (1997). Isolation and analysis of functional homologues of the secretion-related SAR1 gene of Saccharomyces cerevisiae from Aspergillus niger and Trichoderma reesei. Mol Gen Genet 256, 446-455.

Verdoes, J. C., Punt, P. J., Strouthamer, A. H. \& van den Hondel, C. A. M. J. J. (1994). The effect of multiple copies of the upstream region on expression of the Aspergillus niger glucoamylaseencoding gene. Gene 145, 179-187.

Vogel, H. J. (1956). A convenient growth medium for Neurospora (medium N). Microb Genet Bull 13, 42-44.

Ward, M., Wilson, L. J., Kodama, K. H., Rey, M. W. \& Berka, R. M. (1990). Improved production of chymosin in Aspergillus by expression as a glucoamylase-chymosin fusion. Biotechnology 8 , 435-440.

Wessels, J. G. H. (1994). Developmental regulation of fungal cell wall formation. Annu Rev Phytopathol 32, 413-437.

Witteveen, C. F. B., Veenhuis, M. \& Visser, J. (1992). Localisation of glucose oxidase and catalase activities in Aspergillus niger. Appl Environ Microbiol 58, 1190-1194.

Wösten, H. A. B., Moukha, S. M., Sietsma, J. H. \& Wessels, J. G. H. (1991). Localization of growth and secretion of proteins in Aspergillus niger. J Gen Microbiol 137, 2017-2023.

van den Wymelenberg, A. J., Cullen, D., Spear, R. N., Schoenike, B. \& Andrews, J. H. (1997). Expression of green fluorescent protein in Aureobasidium pullulans and quantification of the fungus on leaf surfaces. Biotechniques 23, 686-690.

van Zeijl, C. M. J., van de Kamp, E. H. M., Punt, P. J., Selten, G. C. M., Hauer, B., van Gorcom, R. F. M. \& van den Hondel, C. A. M. J. J. (1998). An improved colony-PCR method for filamentous fungi for amplication of PCR fragments of several kilobases. J Biotechnol 59, 221-224.

Received 9 April 1999; revised 11 October 1999; accepted 28 October 1999. 